\title{
MENTAL HEALTH PROMOTION POLICY: UNDERLINING BIOETHICAL ASPECTS
}

\section{POLÍTICAS DE PROMOCIÓN DE LA SALUD MENTAL: ASPECTOS BIOÉTICOS DESTACADOS}

\author{
Sara Mora Ugalde \\ Universidad Nacional, Costa Rica \\ sara.mora.ugalde@una.ac.cr
}

\author{
Alexander Téllez Aguilar \\ Universidad Nacional, Costa Rica \\ alexander.tellez.aguilar@una.ac.cr
}

Recibido: 4 de marzo de 2021 / Aprobado: 19 de abril 2021 / Publicado: 1 de octubre

\begin{abstract}
Mental health is one of the areas that needs to be addressed as part of the spectrum contained in a comprehensive conception of health, it must be included in public policies of the government with particular importance. Mostly in a country in where the strengths include robust public health care system such as Costa Rica. Hence, the Ministry of Health presented the National Mental Health Policy in 2012 and it is meant to be concluded this year. This paper examines the principles and approaches defined in this policy through bioethical lenses. The results include the description of the ethical proposal mentioned and establish the importance of analyzing similar aspects in forthcoming proposals using bioethical knowledge.
\end{abstract}

Keywords: Bioethics, mental health, public policy, global justice, precautionary principle.

\section{Resumen}

La salud mental es una de las áreas que deben ser tomadas en cuenta como parte del espectro contenido en una concepción de la salud, que debe verse reflejada en las políticas públicas de un Estado, con particular importancia, en un país cuyas fortalezas incluyen un sistema robusto de salud pública como en Costa Rica. En respuesta, el Ministerio de Salud presentó en el 2012 la Política Nacional de Salud Mental, que está programada para terminar este 
año. En este artículo, se examinan los principios y enfoques definidos en esta política por medio de lentes de bioética. Los resultados incluyen la descripción de la propuesta ética mencionada y establecen la importancia de realizar un análisis de aspectos similares en propuestas futuras, al utilizar el conocimiento bioético.

Palabras clave: Bioética, salud mental, política pública, justicia global, principio de precaución.

\section{Introduction}

Mental health is essential for the development of human capacities which can be projected to a better coexistence, not only at the individual level but also at the social scale. The National Mental Health Policy 20122021 was formulated to provide strategies to achieve good mental health for the Costa Rican's population. This policy was planned based on specific principles and approaches described in the document, not only to evaluate mental health on a specific area, but also those elements that manage to promote an improvement in people's living conditions.

This article underlines the aftermath of the Ministry of Health's proposal, focused on principles and approaches, for the development of future mental health policies in Costa Rica, including the remarks on the complementary agenda. It responds to a research presented by the Ministry of Health of Costa Rica in 2020, where it critically analyzes the National Mental Health Policy 2012-2021. First, through a bibliographic review to contextualize the policy; historically and politically. Second, an analysis of the policy itself, searching for principles and approaches and their respective descriptions, to identify its closeness to bioethical proposals.

It is convenient to examine this policy and, particularly, its philosophical basis through critical and discourse analysis, as it is both a health and an ethical issue. As an effort made by the interaction of several actors, whose governmental positions allow them to change the country's course in terms of mental health, this article presents an analysis of this first proposal, that needed to be reviewed as a foregoing action to establish strong ethical basis for the next Mental Health Promotion Policy. 


\section{The Policy}

Advised by the Ministry of Health of Costa Rica (2012), the National Mental Health Policy is the answer provided to strengthen the mental health of the country's inhabitants and prevent early disability, embracing attention, healing, and rehab beyond the biologist attention paradigm (p. 9-11). On one hand, the political environment made this project viable, including the 2010-2014 Government's Plan at a local scale and the strategy and action plan about mental health (WHO, 2009) from the multilateral scenery. On the other hand, mental health is an issue that has not been effectively addressed by public policies before. (Ministry of Health, 2012, p. 13) This offered an opportunity for providing guidelines in a field justified by the Costa Rican population's needs.

Along with this view, but including the economic aspect, the proposal was qualified as essential considering that international studies indicated that by $2030,35 \%$ of economic burden due to illness will be due to mental fields, surpassing $30 \%$ of cardiovascular disease (Ministry of Health, n.d.), to justify the investment involved in this policy, based on the future need for productivity and job continuity. Indeed, a loss of $\$ 16$ trillion is estimated globally between 2011 and 2030 due to direct costs and lost income attributable to mental disorders (Bonnie \& Zelle, 2019, p. 2) and that estimation was made before the pandemic, which also has had an impact on mental health.

The policy was the result of the interaction between private and public institutions, non-governmental organizations, patients' associations, and the Pan American Health Organization (Ministry of Health, 2012, p. 10). One of the main implications on the public human resources was the designation of a new Vice-minister in charge of mental health (Ministry of Health, 2012, p. 15). In Costa Rica's case, the National Mental Health Policy is supported by article 21 of the Political Constitution of the Republic of Costa Rica, which dictates that "Human life is inviolable." Moreover, the Costa Rican government is obliged to ensure the stability and well-being of its citizens, to achieve healthy, free, and equitable environments that enhance life in general.

It should be emphasized that, following the WHO's (2004) line regarding the monitoring of these guarantees, "Mental health is not only the responsibility of the ministries of health. It requires the participation of a wide range of sectors, actors, and stakeholders.” (p. 25) As already indicated, 
Mental Health is related to a diversity of factors, such as political, cultural, economic, etc., which circumscribe the integral nature of what is understood by mental health; hence, such a state of well-being not only involves physical health (where health institutions would be involved) but also all those areas already mentioned. Therefore, the policy has a multisectoral sense, which involves all those sectors that have interference in people's lives.

Related to mental health, the policy states that the main principles are equity, universality, solidarity, substantive equality, ethics, quality and warmth, and autonomy, (Ministry of Health, 2012, p. 42-43) providing a short description of each of them. The policy also has lines of transversal approach that seek to be reflected in its proposal. Focusing on community attention, it intends to include "human rights, gender, diversity, integration, social inclusion, social participation, sustainable human development, scientific evidence, and good practices" (Ministry of Health, 2012, p.11).

As stated in this policy, the importance of promoting mental health lies in optimal development of individual and social conditions, while, as mentioned in the policy "Health is essential for the complete enjoyment of life, it allows the development of human potentialities and social interaction. Mental Health is an indissoluble part of Health" (Ministry of Health, 2012, p. 11). For this reason, the document considers aspects not only related to physical health, but also to environment, and health systems in the development of good mental health.

\section{Health Includes More Than Physical Body Wellness}

This policy was conceived considering "biology, environmental, social-economical-cultural, health systems and services, and institutional strengthening." (Ministry of Health, 2012, p. 11) It intends to respond beyond physical indicators. The biologist approach has long been predominant in the country, a model strengthened by the creation of a specialized hospital (National Psychiatric Hospital), that segregated mental illnesses, until in 1961 a psychiatric service was established for the first time in a general hospital (Dr. Rafael Ángel Calderón Guardia Hospital) (Ministry of Health, 2012, p. 13), which does not imply a comprehensive conception of mental health, but recalls that mental health services in Costa Rica have been insufficient and stigmatized. Mental health, due to this extension started to be considered as 
part of health services in every hospital, in a more integrated view, in general, medical services. Though, specific psychological and psychiatric attention may need to be strengthened.

In Costa Rica, health is a legal asset of public interest protected by the government (Health General Law N ${ }^{\circ} 5395$, first article). This includes ensuring the population's health. On March 4th, 2014, the Health General Law was changed due to the creation of the Technical Secretary of Mental Health; afterwards, article 9 includes:

All people have the right to the promotion of physical and mental health, prevention, recovery, rehabilitation, and access to services at different levels of care and settings, as well as the availability of proven treatments and medications' quality. The attention will be carried out, mainly, at the community level. To do this, outpatient care resources, partial hospitalization systems and home care will be used, and those problems of minors, people with disabilities, the elderly and people with disabilities will be specially considered. Depression, suicide, schizophrenia, drug and alcohol addictions, school bullying, workplace bullying and the necessary support to the family group. Placement will be used only in absolutely necessary cases. (Health General Law N5395, 9th article)

Modifications were made also concerning information, promotion, and preservation of mental health as a right to be obtained from competent government officials (Health General Law N ${ }^{\circ} 5395,10$ th article). But what is mental health? The World Health Organization defines health as "a state of complete physical, mental, and social well-being and not merely the absence of disease or infirmity."1 Mental health is a specification within the health issue, which means that it cannot contain within itself all the elements that imply health because they are not synonyms. However, the mind is an essential element in the human being, as Aristotle pointed out that the aspect that made humans different from other animals is to be the rational capacity. So, the mind, which houses the possibility of exercising that rationality,

1 The preamble to the Constitution of WHO as adopted by the International Health Conference, New York, 19 June - 22 July 1946; signed on 22 July 1946 by the representatives of 61 States (Official Records of WHO, no. 2, p. 100) and entered into force on 7 April 1948. 
assumes to be a privileged element in the human being. Therefore, to speak of mental health should be a core axis in the integral health of any person.

Mental health is a necessary aspect for being healthy and is not included just in physical areas, as it needs to consider more than visible manifestations of illness, as stated by the WHO (2018) as "a state of well-being in which an individual realizes his or her abilities, can cope with the normal stresses of life, can work productively and is able to contribute to his or her community". This aims to include multiple factors in social, psychological, and biological fields. In other words, beyond analyzing physical body manifestations, mental health is an integral approach, which needs to consider the environment where the individual's development takes place.

The definition made by the commission that wrote the policy, describes mental health as: "a process of well-being and personal and collective performance characterized by self-realization, self-esteem, autonomy, the capacity to respond to the demands of life in various contexts: family, community, academic, work, and enjoy life in harmony with the environment." (Ministry of Health, 2012, p. 34) Defining mental health is a major task since it also defines what should be considered as unhealthy mentally speaking. This definition seems to be individually centered, placed in concepts related to the capacity of each person to face life and take decisions. It could be ensured that mental health is related to the possibility of people to control their life and choose. In this sense, reflection on one's conditions or capacities is essential. For example, for Seneca (2008), having self-control implies not being disturbed by external things, that is, not craving what is not possible to achieve. In this process, the exercise of reason has a fundamental role since it is the reflection of the reflective capacity of people to know their own capacities. Thus, mental health is a fundamental element in the exercise of autonomy. In other words, the regulation of decision-making is determined by the mental capacity of the individual. Though autonomy and mental health are effectively related, if this definition is accepted, there is a risk of centering health in a private context, which may lead to poor actions in the public field. This is important, because this policy is intended to address a public issue, and "the concept of mental health is essential to understanding the problems it was intended to solve, and what it may use for the future." (Manwell, 2015, p. 10) 
There have been different definitions of mental health, one of the most preferred is the one provided by the Public Health Agency of Canada: "Mental health is the capacity of each and all of us to feel, think, and act in ways that enhance our ability to enjoy life and deal with the challenges we face. It is a positive sense of emotional and spiritual well-being that respects the importance of culture, equity, social justice, interconnections, and personal dignity." (Manwell, 2015, p.3) These definitions add a sense of value to emotional and spiritual well-being, not only to react or "respond to demands of life," but to it also introduces aspects to promote a better interaction in society, as it includes equity, social justice, and personal dignity.

Mental health can be conceived depending on the individual, referring to it in terms related to autonomy, as Mental Health Promotion Policy did. But circumscribed in a context of public policymaking, it should require a more communitarian approach, that allows the development of capacities (Amartya Sen) or the flourishing (Martha Nussbaum) of people, increasing the chances of having optimal mental health, by considering it to be a transversal aspect that needs to be addressed in many other state programs, to link areas that have an impact on human mental health and to promote people participate in their communities.

\section{Principles and Approaches}

Under the heading of policy principles and approaches, the document refers to dignity and human rights as a base to be consistent with. Thus, this needs to be included as transversal guidelines. Dignity has been included in several international instruments, but it is usually not defined, as happens in this policy, though it is a referent to justify why, without distinction, every human being is meant to be addressed as a subject of respect. Therefore, it may be related to human rights, without a concept as dignity, there will be an emptiness in the justification of declaring rights on a universal scale.

Meanwhile, human rights are not static nor definite, because humanity faces new challenges; besides the fact that compliment and fulfillment are determined by everyday human actions. On general qualities, human rights should be universal, absolute, non-negotiable, inalienable, and possible to be exercised (including the possibility to demand its protection) (Cortina, 2000). Costa Rica has been a country that confirm its interests on human 
rights, ratifying 13 international human rights treaties (ODS, 2014), which explains the inclusion of this transverse axis. Dignity and human rights have a historical background in Costa Rica, and a theoretical relation.

The policy also states that the main principles to lead the proposal, which are: equity, universality, solidarity, substantive equality, ethics, quality and warmth, and autonomy (Ministry of Health, 2012, p. 42-43), providing a short description of each of them.

Equity is presented as related to social justice, defining two slopes, one that declares that ideally, each person should have the opportunity of achieving their health potentiality, and the other one refers to avoiding discrimination. (Ministry of Health, 2012, p. 42) Following this description does not guarantee that equity will be achieved, because on the first statement, ideal conditions are only suggested, not demanded. The other part of the description means that no one should be discriminated, but that does not mean "the absence of avoidable or remediable differences among groups of people" nor to help "empower the group in question through systematic changes, such as law reform or changes in economic or social relationships." (WHO, n.d.). Also, equity could be extended as a search to reduce disparities, in this case, could be an opportunity of strengthening public health efforts, because "many social disparities are risk factors for mental illness, and mental illness often widens social disparities." (Bonnie \& Zelle, 2019, p. 3)

The second principle is universality, which is exposed in the policy as a characteristic of human rights that guarantee access to a quality health care system without distinction of sex, gender, age, socioeconomic class, culture, among others. (Ministry of Health, 2012, p. 42) Usually, as a condition expected to be accomplished by principles, it reminds of Kant's categorical imperative; but in this case, it refers specifically to one of the seventh philosophical principles of the Caja Costarricense de Seguro Social (The Costa Rican Social Security Fund, CCSS), which intends to cover every inhabitant without distinction. This is very similar to the first principle of equity, referring to avoiding discrimination, with the only distinction on the potential achievement of each person's health. As it is presented, the "universality" principle may be included in the first "equality" principle; therefore, it should not be required, at least it is just mentioned to underline CCSS's institutional principles, which is only one of the institutions that integrate this proposal. 
Solidarity is explained as one of the fundamental pillars of modern ethics, through which people feel and recognize united and sharing obligations, interests, and ideals. (Ministry of Health, 2012, p. 42) Pointing out the connection to fraternity, and referring to it as the interest in others, the philosopher Cortina recommends the use of an adjective that accompanies solidarity, and that is "universal", to differ from a particular interest of members of group solidarity and extend it to everyone affected by their actions (2003, p. 242-244).

In the Costa Rican social security system, it is a fact that everyone must contribute economically and proportionally to sustain national health services. In this context, solidarity goes beyond the paper and into actions, because the sole action of working in this country, includes the fact of contributing to the system of public health (though there are informal workers too). This should be reinforced as a perception of being part of a major system justified in equity, allowing more participation of citizens, since it's commonly perceived as an obligation rather than the true sense of unity.

The fourth principle included is substantive equality: referring to equality between men and women in terms of rights and opportunities, including equal treatment to both genders mentioned according to the inequalities they may face. (Ministry of Health, 2012, p. 43)

Though the description of "universality" may seem to be somehow alike, in the sense of excluding discrimination, it is important to mention that in Costa Rica, "in recent years there has been a resurgence of discriminatory, sexist, and racist tactics, discourses and sociocultural patterns that follow reproducing inequality and violence (...) it constitutes an obstacle to the advancement of women's human rights." (INAMU, 2018, p. 21) Instead, discrimination problems beyond men and women distinctions need to be addressed too and may be included in the two first principles: equity and universality, as they are defined in the policy. This means three of the selected principles may be referring to the same content. As "gender" is presented in the Policy as one of the main approaches that have to be observed in the proposal, it may not be necessary to use include the "substantive equality" specification.

Ethics is exposed as a principle that analyses, orients, and dictates actions and proceedings, refers to respect to all human beings, dignity, integrity, autonomy, and protection, also to wellbeing and social justice. (Ministry of 
Health, 2012, p. 43) To find "ethics" mentioned as a principle is awkward and inadequate, since it is one of the main fields studied in philosophy, and contains a vast variety of theories and methods, rather than a limited group of words. It is usually conceived as a part of the philosophy: "Ethics is (...) in that dimension of philosophy that reflects on morality." (Cortina, 2000, p. 29) As a practical field, it explores current issues such as the relation of human society and nature; therefore, ethics should not be included as a principle, but as an approach. It is relevant to also identify the ethical slope that the policy will be circumscribed on since there are many differences of thought within ethics.

Quality and warmth are exposed as: The capacity of the health system to guarantee and secure satisfactory solutions to the needs of people is presented as the sixth principle, searching for enlarging benefits and diminishing sickness and death (Ministry of Health, 2012, p. 43). This principle should also be referred to justice since it has great concordance with the need of responding to society, due to the public health care system and responding to the management of public funds. Though, it may also be included from a benefits perspective, to enhance the quality of service.

The last principle, autonomy, is described as the capability to control and take personal decisions and develop day-by-day activities, according to laws and personal preferences (Ministry of Health, 2012, p. 43). Autonomy refers to the right exercised by an agent when making decisions freely, without coercion, although this involves major complications of definition, in a general way it establishes that "respecting an autonomous agent implies, at a minimum, assuming their right to have their own opinions, to choose and to carry out actions based on both their values and their personal beliefs" (Beauchamp \& Childress, 1999, p. 117). Informed consent derives from this principle, in which it is promoted that when faced with treatment or participation in experimentation, there should be exposed most fully, the pertinent information to the subject so that the person makes an informed decision about the acceptance or rejection of the activity. Linked to the ability to give laws to oneself, autonomy states as empowerment, meaning information to take decisions should be a priority.

If someone has a Mental Health problem, the health system should provide the complete information to help that person make an informed 
choice, but before that, the whole system should take measurements to seek the necessary considerations for the understanding of the information and the respect of an autonomous agent. Being an autonomous agent implies the right to be different from others and to carry out actions based on the value system that constitutes it. Conversely, the exercise of this autonomy is subject to certain moral considerations that have a correlation preventing this exercise from doing any kind of harm to others. The conflict with this concept in the field of bioethics is when it is taken absolutely, either as absolute respect or considering it a single value in medical practice.

To avoid this type of conflict, it is necessary to have a balance between the informed knowledge of the patient about their situation and the timely intervention of the medical professional that, in most cases, does not necessarily match the patient's will, but they must take care of him as much as possible to preserve the good health of the patient (principle of beneficence). Though, this brings certain drawbacks, "In medicine, there is the temptation to use the authority of the doctor to favor or perpetuate the dependence of patients, instead of promoting autonomy. But to respect the autonomy of patients, they must be prepared to stop feeling dependent and achieve all possible or desired control of the situation" (Beauchamp \& Childress, 1999, p. 119).

To achieve this last objective, Adela Cortina (1996) offers the concept of self-possession, which according to the author: "[...] a man ultimately seeks to appropriate those possibilities that help him to possess himself' ( $p$. 99). Cortina points out that this self-possession highlights the relationship between morality and biology since this condition goes through the control of the mind and body of the person. The inability to control in any of these aspects is a symptom of disease, so the subjects must find a way to correct it. He points out that self-possession is a personal project that involves everything that surrounds it: [...] Requires as a necessary condition, although not sufficient, the self-esteem of the subject, the awareness that they may have different projects capable of inspiring and that they have the capacities to carry them out. The projects will be singular for different people, and that is why finding one's own is one of the great personal and community tasks, but it is essential to be aware of them and that you have a certain capacity to carry them out. (Cortina, 1996, p. 100). 
Besides, the National Mental Health Policy is structured from certain approaches, needed to sustain the implementation of the strategies that may guide the promotion of mental health in Costa Rica. Such approaches are 1. Human Rights, 2. Gender, 3. Diversity, 4. Integration, 5. Social inclusion, 6. Active participation, 7. Sustainable human development and 8. Scientific evidence and good practices in mental health.

Likewise, the politicization of this approach would lead, as proposed by this plan, to effective planning not only of the resources destined for the improvement to be achieved, but also aims to link different social and political actors involved in the human field. Under this assumption, it is convenient to suggest that the approach in charge of this achievement is Human Rights (the first approach advised on this policy). It must be considered that although the Universal Declaration of Human Rights has served as a general reference to frame this type of discussion, it has been treated critically, precisely because of that "universal" character, which obviates the specifications of the different social groups existing today, which explains why it is essential to examine them within each context. This argument does not mean they should be discarded, but that a review is needed to avoid such abstractions must be part of the equation.

Despite the above, the role of this international instrument is notorious in guidelines. For example, in the document issued by the WHO (2004), entitled Invest in mental health, serious problems related to the lack of respect of human rights in patients with mental disorders are denounced. According to the document "In many countries, these people have limited access to the mental health care they require, given that they do not have services in their area of residence or because they are scarce throughout the country." (p.12) Therefore, there are no minimum conditions for better development health, but general health. In accordance with this, the legislation on mental health issued by the WHO guarantees the protection of the patient's human rights with some type of mental disorder. In this sense, the politicization of how the issue of mental health is treated arises since, through clear legislation on the matter, it is possible to regulate the way in which health institutions provide adequate care to people patients who need certain mental health care.

In concordance, the National Mental Health Policy 2012-2021 is based on a very generalized definition of what is understood by Human 
Rights. According to the policy, Human Rights are “(...) the rights inherent to human person and their dignity, which aim to guarantee equality, dignity, social justice and freedom for all people without any discrimination." (2012, p.43). As stated by the policy itself, the State must guarantee compliance with all practices that promote the development of human faculties and prevent their most fundamental rights from being violated ${ }^{2}$. Considering this perspective, Mental Health is an element of great relevance for this. Therefore, it is important to recover what the WHO maintains about the role of human rights as a regulatory framework; according to this organization: "Human rights empower individuals and communities to grant them privileges that arise legal obligations on government's part. They also help to equalize the distribution and exercise of power within the society, thus mitigating the impotence of the poor." (WHO, 2004, p. 25). It is known that the conditions of inequality have a determining role in the violation of Mental Health. In this way, human rights have the capacity to protect and guarantee equal and non-discriminatory access to health systems for people in situations of vulnerability, but not only as patients, but also as active people in the capacity to participate in this type of policies.

Following Human Rights, the gender approach continues to strengthen equity and non-discrimination expressing that: "It recognizes the existence of opportunity gaps that have been built between men and women, it considers the particularities of each gender and the social implications that these particularities entail. Therefore, the actions taken based on the policy will tend to reduce these gaps, promoting non-discriminatory environments." (Ministry of Health, 2012, p. 43) In addition, article 33 of the Political Constitution states that "Every person is equal before the law and no discrimination against human dignity may be practiced." Therefore, the policy intends to correct the gender specificities that are not contemplated in the Political Constitution.

2 In this sense, the Sustainable Human Development approach pointed out in the policy that "It is the recognition of the state's responsibility to generate conditions for the well-being and development of people in a context of environmental, social, and economical sustainability" (Ministry of Health, 2012, p. 45) In this way, it is expected that the actions that arise from the policy will have a direct impact on the improvement of the external conditions of people that in one way or another affect the stability of mental health. To achieve this, the policy must have a scientific character in the sense that for evaluation and creation of intervention strategies in mental health, it must make use of concrete, reliable and methodological studies that validate them. This corresponds to the Scientific Evidence and Good Practices in mental health's approach. 
It is vital to note that the National Institute of Statistics and Census (INEC) issued a study on gender violence entitled Unified System for Statistical Measurement of Gender Violence in Costa Rica: Indicators 20122016 show the urgency to address violence against women. In this regard, it points out that the Costa Rican State has signed several conventions related to the issue, including the Convention for the Elimination of All Forms of Discrimination against Women (CEDAW), in addition to the Inter-American Convention to Prevent, Punish, and Eradicate Violence against Women. Although it is true that the problem of violence concerns all people over the years, there have been systematic violations against women's rights, and in the specific case of Costa Rica, the need to collect related data arose with this phenomenon. The weight of this lies in the creation of the necessary mechanisms from the data collected in this type of study, to combat violence against women, which in relation to mental health, has direct repercussions that affect the stability of this population in a situation of vulnerability.

In relation to the foregoing and framed in the subject of Human Rights, it is established that "Respect for diversity allows the integral assessment of the person regardless of sex, age, ethnicity, nationality, sexual orientation, and gender identity, among other characteristics, thus contributing to the preservation of Mental Health." (Ministry of Health, 2012, p. 45) In this regard, it should be noted that at the time of the creation of the policy there was no legal framework that would allow the specific control of the issue of diversity, in any of the ways cited by the policy in question. For example, it was until 2017 that through the publication of Legislative Decree No. 9456, the multi-ethnic and multi-cultural recognition of the Costa Rican State was guaranteed. On the other hand, in mid-2020 equal marriage came into force. Despite advances in these matters, there are sectors of the Costa Rican population that show reluctance to recognize the equality of conditions that arise from diversity.

Considering the above, it could be suggested that the root of a large part of the mentioned problems are due to the atomization of the social network. To cover this aspect, the Integration and Social Inclusion approaches look for a way to solve such problems. These approaches suggest that, on the one hand, integration is "the real possibility of involving all social actors in the given geographic population space, to develop strategic alliances that allow 
them to solve development and welfare problems." (Ministry of Health, 2012, p. 44) This, added to the Active Participation Approach of the different social actors, seeks to mobilize these to achieve effective actions that guarantee the improvement of living conditions related not only to mental health but to life in general.

\section{Complementary Agenda}

This section includes social values that should be included on next policies related to mental health, since the authors agree with the policy when it says that "An effective social participation occurs when the community intervenes closely in the economic, social, cultural, and political processes that affect their lives, as a collective, deliberative, democratic and concerted action of people, social groups and their organizations." (Ministry of Health, 2012, p. 44) As mentioned before, Mental Health is also an issue that involves the politicization of aspects that were previously considered exclusively from a purely biological point of view. Hence, the policy starts from the fact that mental health shares the dynamics established from social, cultural, and political determinations, which is why it insists on its integral nature.

To strengthen this policy, it is recommended the inclusion of civic values, comprised in Adela Cortina's proposal of liberty, equality, active respect, solidarity, and dialogue, to prepare human shared existence with the values that make it really human (Cortina, 2003, p. 210). Liberty conceived as participation on public matters (Cortina, 2003, p. 195), taking part in decisions that may lead to politics where the society could be affected, instead of leaving every citizen's common choice, on a small group of stakeholders. Therefore, the empowerment of inhabitants of a country should include spaces of public interaction and education on liberty as defined previously. Liberty is also linked to autonomy, as it deals with the responsibility of the decisions, and has to do with knowledge and personal effort.

Equality expressed on three spheres: on law matters, on opportunities (compensating social and economic inequalities) and on social services, such as the ones provided by the public health care system of Costa Rica. Active respect means not only to tolerate anyone who thinks differently, but to understand them and help them (Cortina, 2003, p. 202), which is closely related to solidarity, which is determinant to live well, not conceived on a 
group scale, but a universal one, trespassing bounders, including future generations. Finally, dialogue which is essential on reciprocal recognition and must be part of decision processes to achieve justice on resolutions of conflicts.

\section{Conclusion Remarks}

The National Mental Health Policy is supported by conceptual approaches that have been developed including other institutions, those interests had to be intertwined towards the interests raised by the Ministry of Health through politics. Through this "theoretical framework", it is expressed that mental health is a fundamental part of health in general, it could even be suggested that most physical conditions are strongly related to mental illnesses, hence the integral nature of the general health concept.

On the other hand, how the policy in question is exposed shows not enough clarity regarding the principles and approaches, expressed for example in the inclusion of "ethics" as a principle. Furthermore, the description could be more extensive, expressing effectively what the policy conceives as each one. Some other considerations should have been included, such as the respect for privacy, since vulnerability may be increased if personal data or worst, clinical information is shared, increasing for example stigmatization or discrimination. Thus, there is a great conceptual void in prejudice to achieve their basic function of clarifying how such principles or axes support the proposal of the Ministry of Health, and that most likely, they have consequences at a practical level, that is, in the strategies proposed from the policy for the treatment of mental health of Costa Ricans.

Therefore, the risk of disarticulation between these principles and the theoretical framework is needed, so that this relationship could give support to the methodology implemented for the development of the activities that are proposed for the analysis of mental health in Costa Rica. In this sense, there is a threat of leaving the National Mental Health Policy 2012-2021 without having a conceptual connection on its basis. If it had been considered differently, the policy structure could be more effective in detecting the underlying problems concerning mental health and thus implementing truly effective strategies to tackle these causes at the root. 


\section{References}

Beachamp, T. y Childress, J. Principios de la ética médica. Masson. España. 1999.

Bonnie, Richard J., and Heather Zelle. "Ethics in Mental Health Care: A Public Health Perspective." In The Oxford Handbook of Public Health Ethics, edited by Anna C. Mastroianni, Jeffrey P. Kahn, and Nancy E. Kass, by Richard J. Bonnie and Heather Zelle, 204-218. Oxford University Press, 2019. DOI: 10.1093/ oxfordhb/9780190245191.001.0001

Cortina Orts, Adela. Ciudadanos Del Mundo: Hacia Una Teoría de La Ciudadanía. Madrid: Alianza Editorial, 2003.

. Ética sin moral. Madrid: Tecnos, 2000.

—. El quehacer ético. Guía para la educación moral. Madrid: Santillana. 1996.

INAMU. Política Nacional para la igualdad efectiva entre mujeres y hombres 2018-2030. Costa Rica, 2018.

Legislativa, A. "Ley General de Salud.” Asamblea Legislativa., 1973.

Manwell, L. A., S. P. Barbic, K. Roberts, Z. Durisko, C. Lee, E. Ware, and K. McKenzie. "What Is Mental Health? Evidence towards a New Definition from a Mixed Methods Multidisciplinary International Survey.” BMJ Open 5, no. 6 (June 2, 2015): e007079-e007079.

Ministerio de Salud. Política Nacional de Salud Mental 2012-2021. Costa Rica, 2012.

ODS. Objetivos de Desarrollo Sostenible. Los ODS, los Derechos Humanos y el Consenso de Montevideo, 2014. https://ods.cr/ los-ods-los-derechos-humanos-y-el-consenso-de-montevideo

Organización Mundial de la Salud. Invertir En Salud Mental. (Ginebra: Organización Mundial de la Salud) 2004.

Organización Mundial de la Salud. Promoción de la Salud Mental: conceptos, evidencia emergente, práctica. (Ginebra: Organización Mundial de la Salud) 2004.

Organización Mundial de la Salud. "Constitución". https:/www.who.int/es/about/ governance/constitution

World health organization (WHO) "Mental Health: Strengthening Our Response, 2018." https://www.who.int/news-room/fact-sheets/detail/ mental-health-strengthening-our-response.

World health organization (WHO), "Health Systems.," Health Systems, N.D. https://www. who.int/healthsystems/topics/equity/en/

República de Costa Rica, Constitución Política. (San José, Costa Rica: Publicaciones Jurídicas), 1994.

Ministerio de Salud Costa Rica, "Especialistas califican de esencial Plan de Salud Mental 2012-2021," Ministerio de Salud Costa Rica, https://www.ministeriodesalud.go.cr/ index.php/noticias/noticias-2012/325-especialistas-califican-de-esencial-plan-de-salud-mental-2012-2021.

Séneca. Diálogos. Madrid: Gredos, 2008.

Institucional, C. T. Sistema Unificado de Medición Estadística de La Violencia de Género En Costa Rica: Indicadores 2012-2016 (Costa Rica: INEC) 2018. 